\title{
Coleção Monumento à Oswaldo Cruz
}

\section{The Collection Monument to the Memory of Oswaldo Cruz}

$\mathrm{L}$ ogo após a morte de Oswaldo Cruz, em 11 de fevereiro de 1917, seus admiradores, amigos e companheiros de trabalho criaram a Fundação Oswaldo Cruz e a Comissão do Monumento à Memória de Oswaldo Cruz. Fundada em 26 de julho de 1922, a primeira destinava-se a perpetuar a memória do saneador do Rio de Janeiro através de obras de assistência, instrução técnica e educação profissional. Seus estatutos incluíam um decálogo em louvor aos princípios que guiaram seus passos de homem de ciência. O último tópico era considerado o lema da fundação: "Na ciência e na instrução, na assistência e no amor que constituiriam a finalidade da obra de Oswaldo Cruz, materializar a glória de sua vida." Os membros mais destacados da Fundação Oswaldo Cruz eram Salles Guerra, presidente; Guilherme Guinle, vice-presidente; Clementino Fraga, secretário; João Pedroso, tesoureiro; Félix Pacheco, ministro da Justiça e Negócios Interiores; Pires e Albuquerque, jornalista; Alfredo Ellis, senador; Carlos Chagas, diretor do Departamento Nacional de Saúde Pública e do Instituto Oswaldo Cruz (IOC); e Miguel Couto, presidente da Academia de Medicina.

Entre as obras de assistência que pretendiam implementar, destacava-se a construção do Instituto do Câncer, destinado "a pesquisas de laboratório, no encalço da causa produtora do mal, com hospital para cancerosos, instalações de radium e raio X". O instituto seria construído a expensas da família Guinle, e, a partir de 1924, foram tomadas diversas iniciativas visando concretizar o ambicioso plano.

Em 1934, o presidente da República, Getúlio Vargas, visitou as construções já iniciadas, prometendo uma verba para a conclusão e o aparelhamento do hospital, mas, no ano seguinte, as obras foram paralisadas por falta de recursos. Guilherme Guinle, em carta enviada a Salles Guerra, presidente da fundação, informou não ter condições de arcar sozinho com o custeio da edificação do hospital e de seus laboratórios.

A dificuldade de encontrar parceiros que pudessem participar do projeto com colaborações vultosas contribuiu de forma decisiva para a extinção da Fundação Oswaldo Cruz, em 25 de julho de 1936. Todo o seu patrimônio foi então transferido para a Comissão do Monumento.

Composta por figuras ilustres, que iriam compor também os quadros da fundação - Miguel Couto, Nascimento Gurgel, Miguel Pereira, Carlos Chagas, Salles Guerra, entre outros - a Comissão do Monumento iniciara suas atividades em 1917, distribuindo listas para sua subscrição nacional destinada a arrecadar recursos para a construção do monumento.

Foi reorganizada em 1927, obtendo, então, personalidade jurídica para receber crédito governamental, e, outra vez em 1935, por haver falecido a maior parte de seus membros. 
No ano seguinte, iniciou-se a transferência dos bens da extinta Fundação Oswaldo Cruz para a comissão, que enviou circular aos interventores e governadores dos estados solicitando auxílio para a realização da obra. Só o Piauí atendeu ao apelo.

Em 1938, a prefeitura do Distrito Federal destinou a praça da avenida Epitácio Pessoa, fronteira ao Corte de Cantagalo, para a localização do monumento, ao mesmo tempo que a comissão instituiu concurso para a escolha do projeto que iria perpetuar a memória de Oswaldo Cruz. O edital, publicado em maio, admitia concorrentes nacionais e estrangeiros. Em dezembro, a comissão recebeu vinte projetos, acompanhados de memoriais descritivos, que foram expostos na Escola Nacional de Belas Artes. O júri, composto pelos profs. Aloisio de Castro, Luis de Anhaia Mello, Carlos Oswald e Godofredo Paulo Silveira Feijó, não elegeu nenhum dos projetos com base na seguinte justificativa:

tendo tudo bem apreciado, verificou e decidiu, por unanimidade de seus componentes, que nenhuma das obras em apreço preenchia verdadeiramente seus fins, nenhuma trazia qualidades capazes, uma vez executado o projeto, de testemunhar o grau da cultura atual do país, ornamentar com monumentalidade e conveniência a metrópole brasileira, na zona escolhida, nem expressar em forma plástica e simbólica o sentimento nacional da obra científica de Oswaldo Cruz.

A comissão resolveu, então, organizar outro concurso. Novo edital foi elaborado e publicado. Em janeiro de 1940, 22 trabalhos, acompanhados de projeto, maquete e memorial descritivo, apresentaram-se à concorrência. Compuseram o júri os profs. Aloisio de Castro, Godofredo Paulo Silveira Feijó, Ernesto de Souza Campos e Augusto Bracet. Dessa vez, classificaram, em $1^{\circ}$ lugar, o projeto 'São Luis de Paraitinga'; em $2^{\circ}$, o projeto

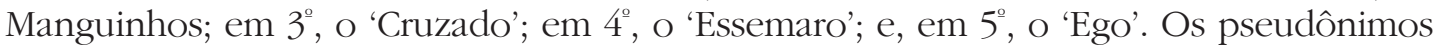
ocultavam os seguintes autores: Julio Starace, Galileu Emendabile, Hildegardo Leão Velloso, Samuel Martins Ribeiro e Humberto Cozzo, respectivamente.

Em agosto de 1941, Julio Starace assinou o contrato definitivo para a construção do monumento, mas, em seguida, surgiram sérias divergências entre o artista e a comissão, envolvendo desde o terreno onde seria erigida a obra até o desembolso das quantias que deveria receber para confeccioná-la.

Desde 1940, a comissão fora recomposta várias vezes. Nos anos seguintes, os desentendimentos com Starace se acirraram a tal ponto que seus membros cogitaram em rescindir o contrato. Quando Olympio da Fonseca assumiu a presidência, em 1952, propôs ao artista que a obra fosse executada por uma construtora. Com a morte dele naquele ano, Julio Starace Filho passou a responder pelo contrato. Decidiu-se, mais uma vez, levantar recursos para concretizar o monumento. As iniciativas não foram bemsucedidas e, em 1958, a comissão chegou a aprovar a instituição de novo concurso, que não aconteceu. Em 1959, os profs. Wladimir Alves de Souza e Mario Barata foram incumbidos de visitar o ateliê do escultor para examinar a obra inacabada. Quando, em 7 de janeiro de 1960, a comissão se reuniu pela última vez, ficou assentado que novo concurso seria realizado, a família Starace seria indenizada e as peças confeccionadas em gesso pelo artista seriam destinadas a instituições relacionadas com a vida de Oswaldo Cruz.

Os pareceres escritos por eles sustentavam que a obra enve-lhecera e questionavam se o monumento deveria ser construído tal como fora concebido. Alves Souza, em sua 
crítica, se mostrava impressionado com "seu aspecto kafkiano. ... Como arquitetura, a composição geral, aparentando compromisso com a arte de nosso tempo, é, em realidade, o que os franceses chamam a grosse machine, de gosto acentuadamente acadêmico e já envelhecido na própria época de sua criação." Na opinião de Mario Barata, "apesar de ter o artista visivelmente superado a si mesmo, em comparação aos seus trabalhos anteriores, não se trata no caso, evidentemente, da existência de uma obra-prima, que se devesse conservar ou concluir a qualquer custo".

O monumento que perpetuaria sua memória nunca foi construído. A documentação referente ao assunto ficou sob a guarda do IOC a partir de 1965. Em 1990, foi recolhida ao Arquivo Permanente da Fiocruz sob responsabilidade do Departamento de Arquivo e Documentação da Casa de Oswaldo Cruz, unidade responsável pela preservação, valorização e divulgação do acervo histórico, científico e cultural da instituição. Após a identificação, a higienização e o arranjo dos documentos, foi elaborado um inventário sumário.

A coleção é composta de 797 itens documentais, dos quais 744 são textuais, 52 fotográficos e um cartográfico, abrangendo o período de 1917 a 1965. Foi organizada nas seguintes séries: Correspondência, Documentação Financeira; Concurso; Recortes de Jornais; Comissão Central — Subscrições e Donativos; Atas, Relatórios, Documentos Cartoriais, Atos Oficiais e Legislativos.

Destacam-se na coleção os memoriais descritivos e as fotos das maquetes que acompanham os projetos apresentados nos concursos, revelando, em primeiro lugar, a visão dos artistas sobre Oswaldo Cruz e seus feitos, sobre a ciência e a medicina. A concepção dos projetos é descrita detalhadamente, como naquele apresentado sob o pseudônimo de Araribóia:

O conjunto arquitetônico que idealizamos simboliza o livro da história do grande e inesquecível discípulo de Pasteur, aberto pela nação (bandeira servindo de marcador de livro), para a contemplação dos povos e como incentivo às novas gerações. Na fachada principal colocamos a figura de Oswaldo Cruz, na sua mesa de trabalho, aonde se conservou até o fim de sua vida, sob a influência da deusa da saúde, Hygea ...

A coleção é um bom testemunho da construção de uma memória nos moldes sugeridos por Michel Pollak: é um fenômeno construído e ainda "elemento constituinte do sentimento de identidade, tanto individual como coletiva, na medida em que ela também é fator extremamente importante do sentimento de continuidade e de coerência de uma pessoa ou de um grupo em sua reconstrução de si" ('Memória e identidade social'. Estudos Históricos; teoria e história. Rio de Janeiro, vol. 5, nํ1스. pp. 201-15, 1992). Podemos supor que a necessidade de afirmar a identidade, a continuidade e a coerência de um modelo que deu sentido à experiência de toda uma geração de homens dedicados à ciência motivou não só a criação das duas entidades referidas, como também explica a permanência durante tantos anos da Comissão do Monumento. 


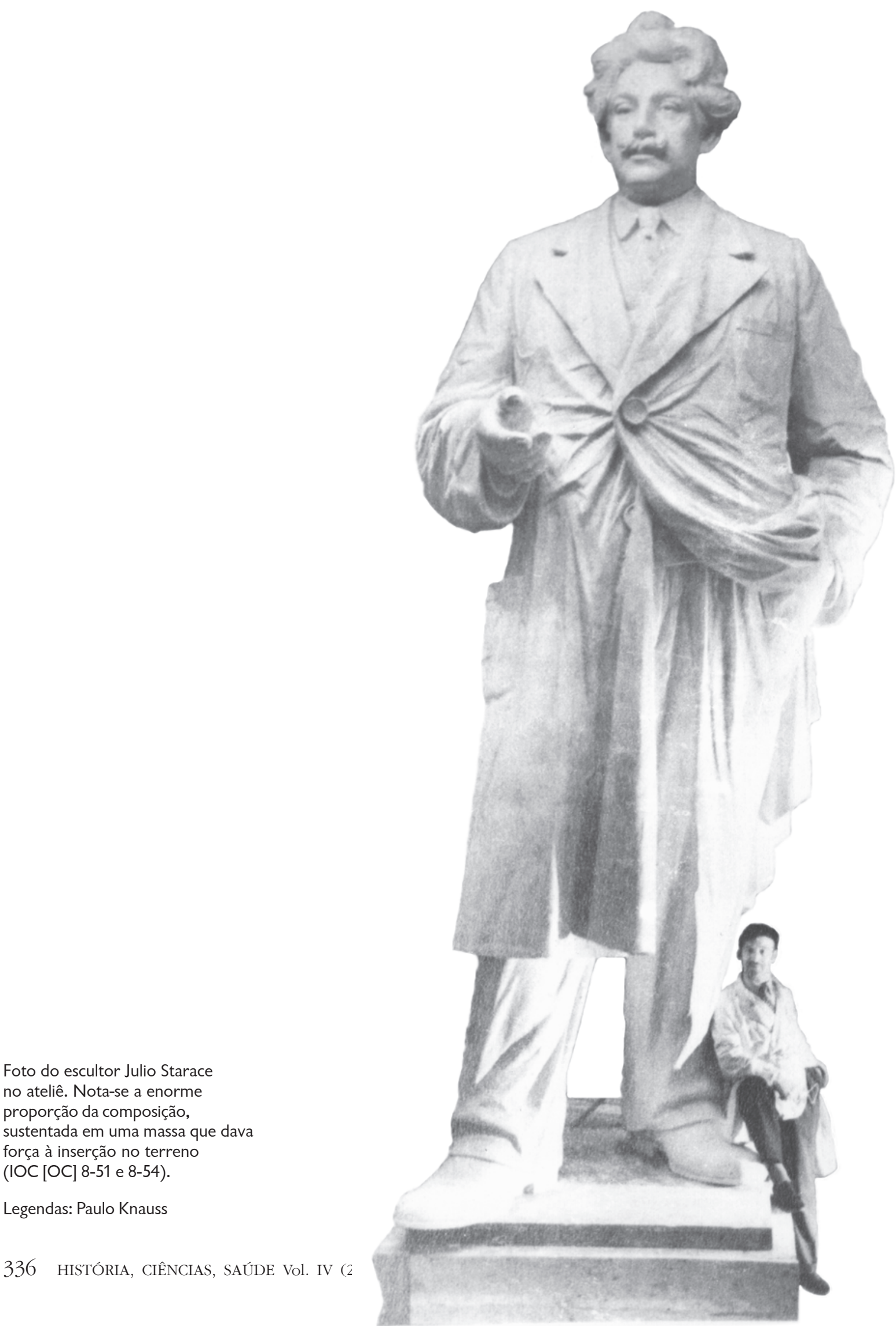




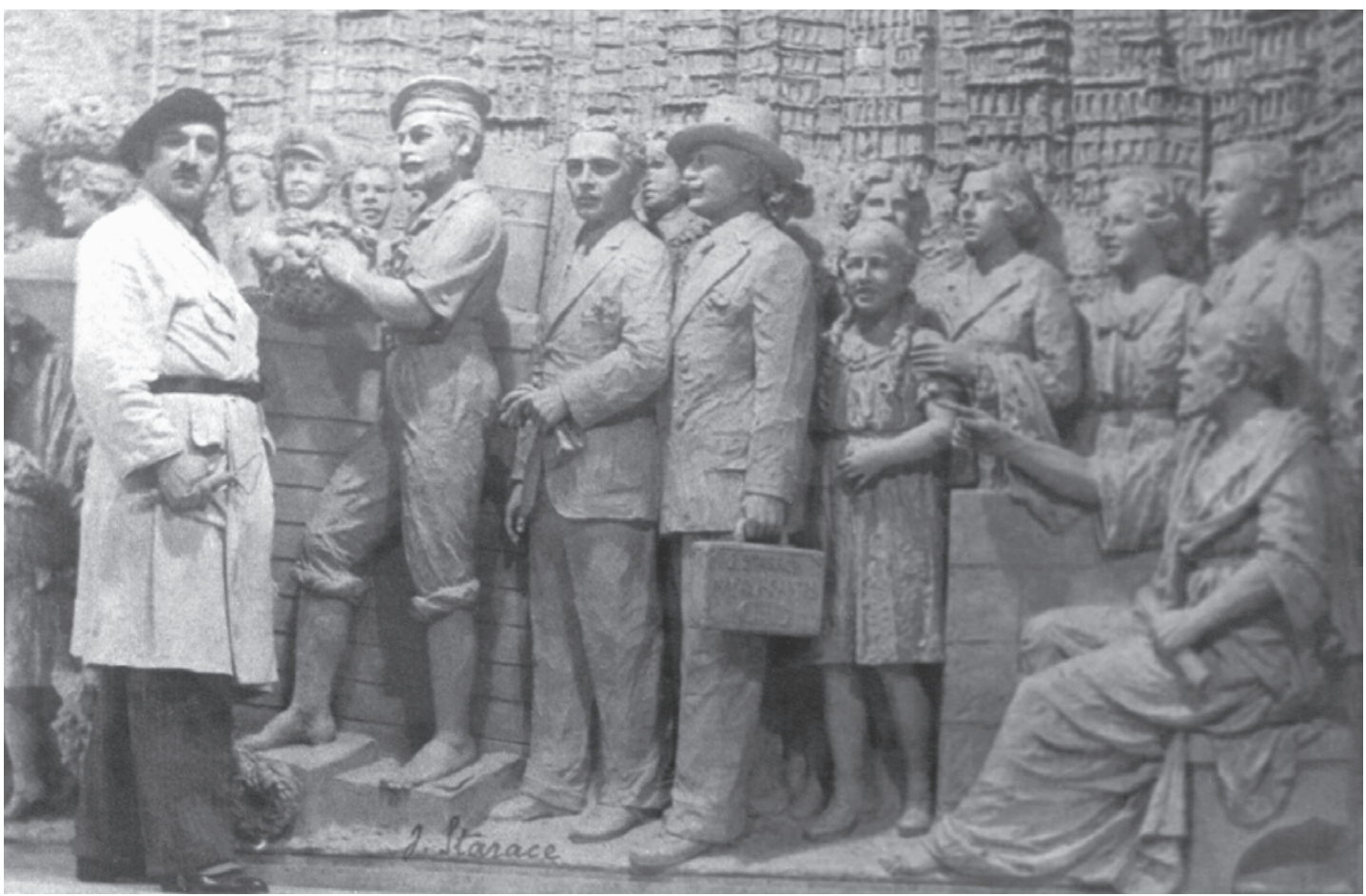

Foto do artista Starace no ateliê. (IOC [OC] 8-51 e 8-54).

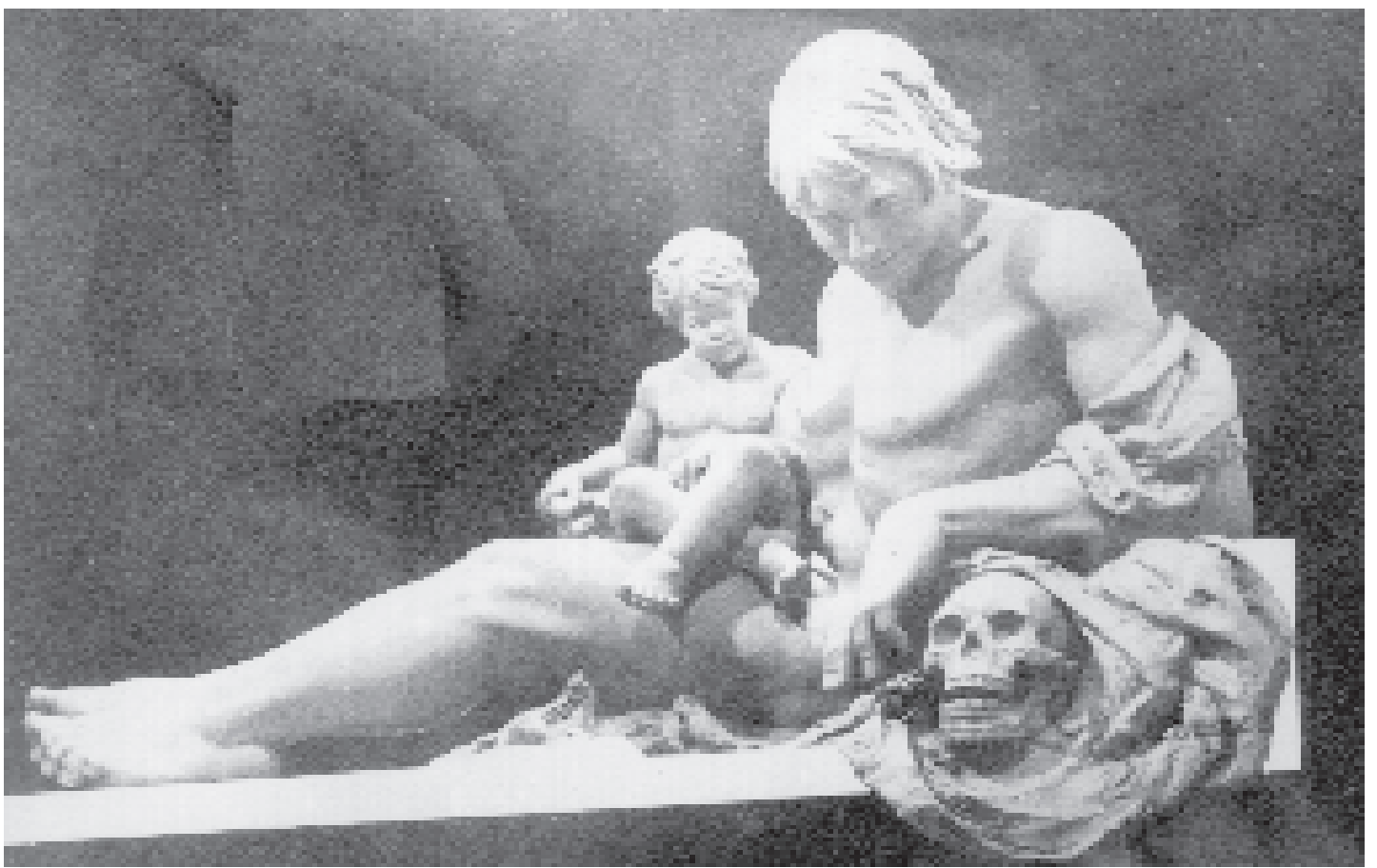

No projeto de Starace, alegorias davam carga dramática à composição, como no caso da caveira, signo da morte, ao lado do pai com uma criança no colo, signo de vida carente de proteção (IOC [OC] 8-32). 
Maquete de monumento de Julio Starace. Vista geral assinada.

A composição de Starace enfatizava o retratismo, colocando a estátua em posição central, e o caráter descritivo com as inscrições e os relevos escultóricos, ilustrativos de cenas da vida do cientista. Uma primeira cena ilustra o combate à varíola e a campanha da vacina obrigatória; outra retrata o combate à peste bubônica e a medicina socorrendo as vítimas; a terceira cena representa a criação do Instituto de Manguinhos, com as figuras dos discípulos procurando cobrir de louros o mestre. Em outra parede, o povo movido pela gratidão cobre de louros o personagem; a cena seguinte representa a exaltação da personalidade; e a última ilustra a extinção da febre amarela. A composição completava-se com outras peças alegóricas e decorativas, uma simbolizando a pátria e a outra a ciênca médica. De um modo geral, se o projeto mantinha-se ajustado aos padrões acadêmicos no tocante à escultura, a solução arquitetônica tornava-o mais atualizado em relação aos parâmetros da época.

(Fundo IOC [OC] 8-21, 8-26 e $8-42$, respectivamente).

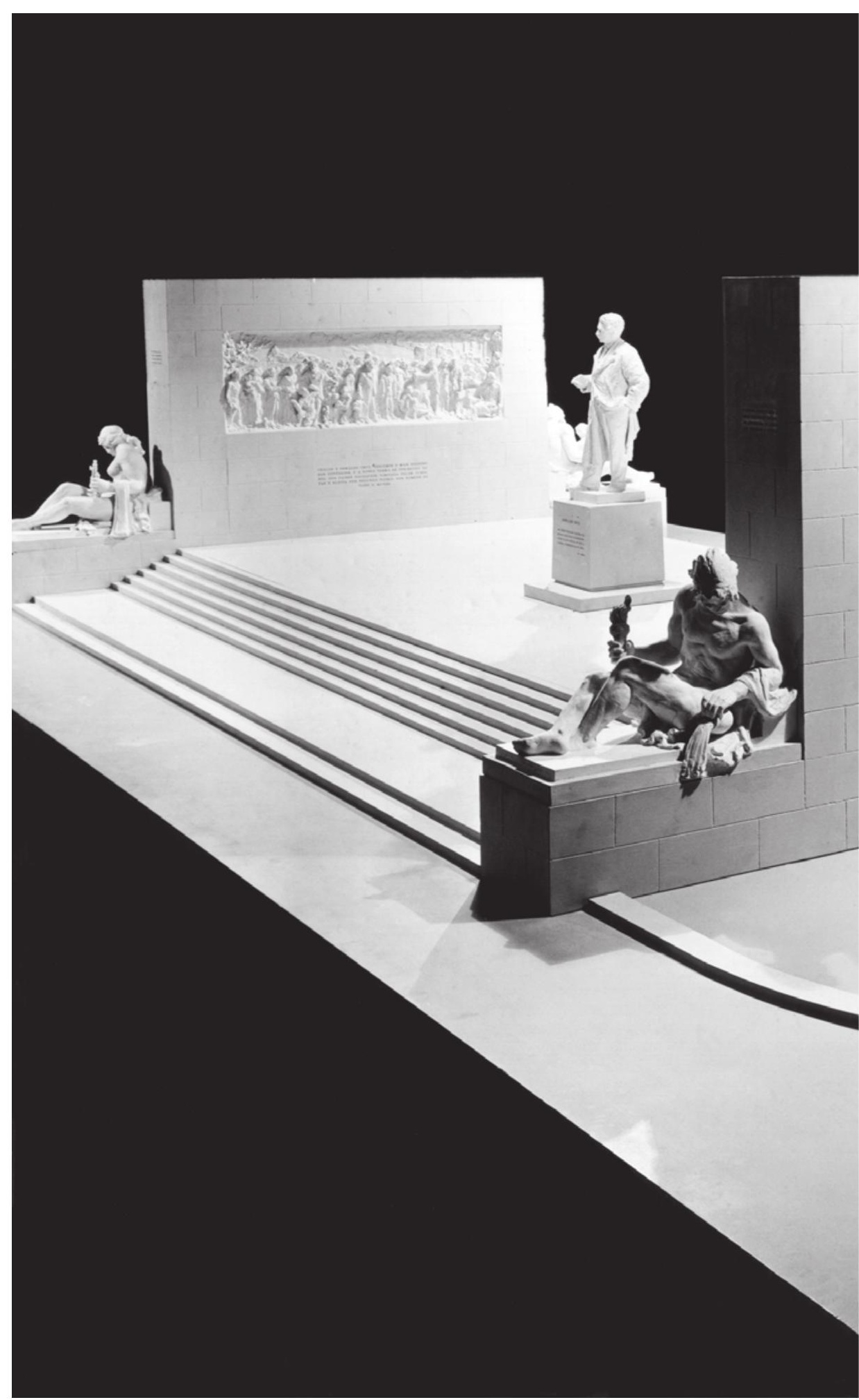




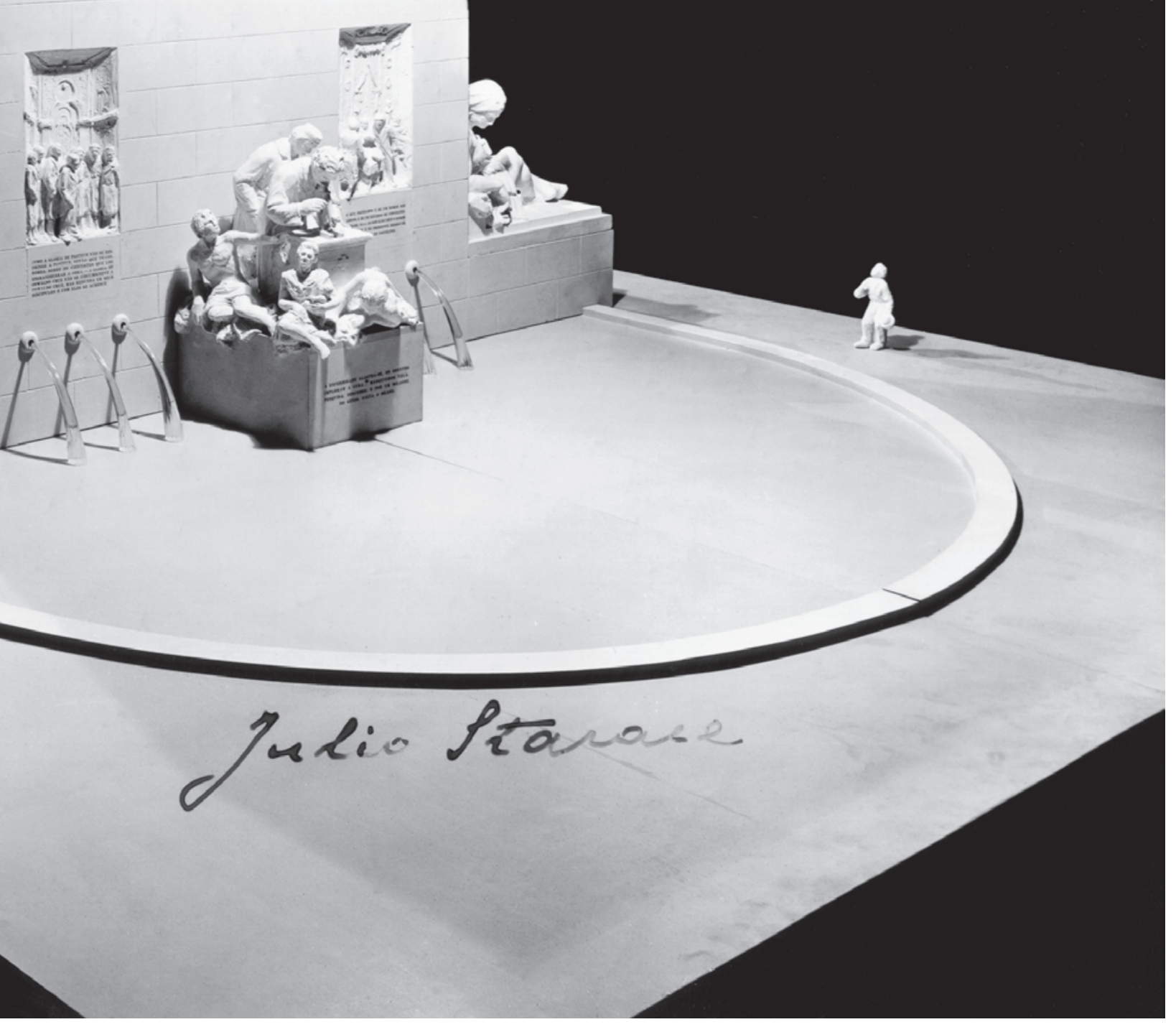




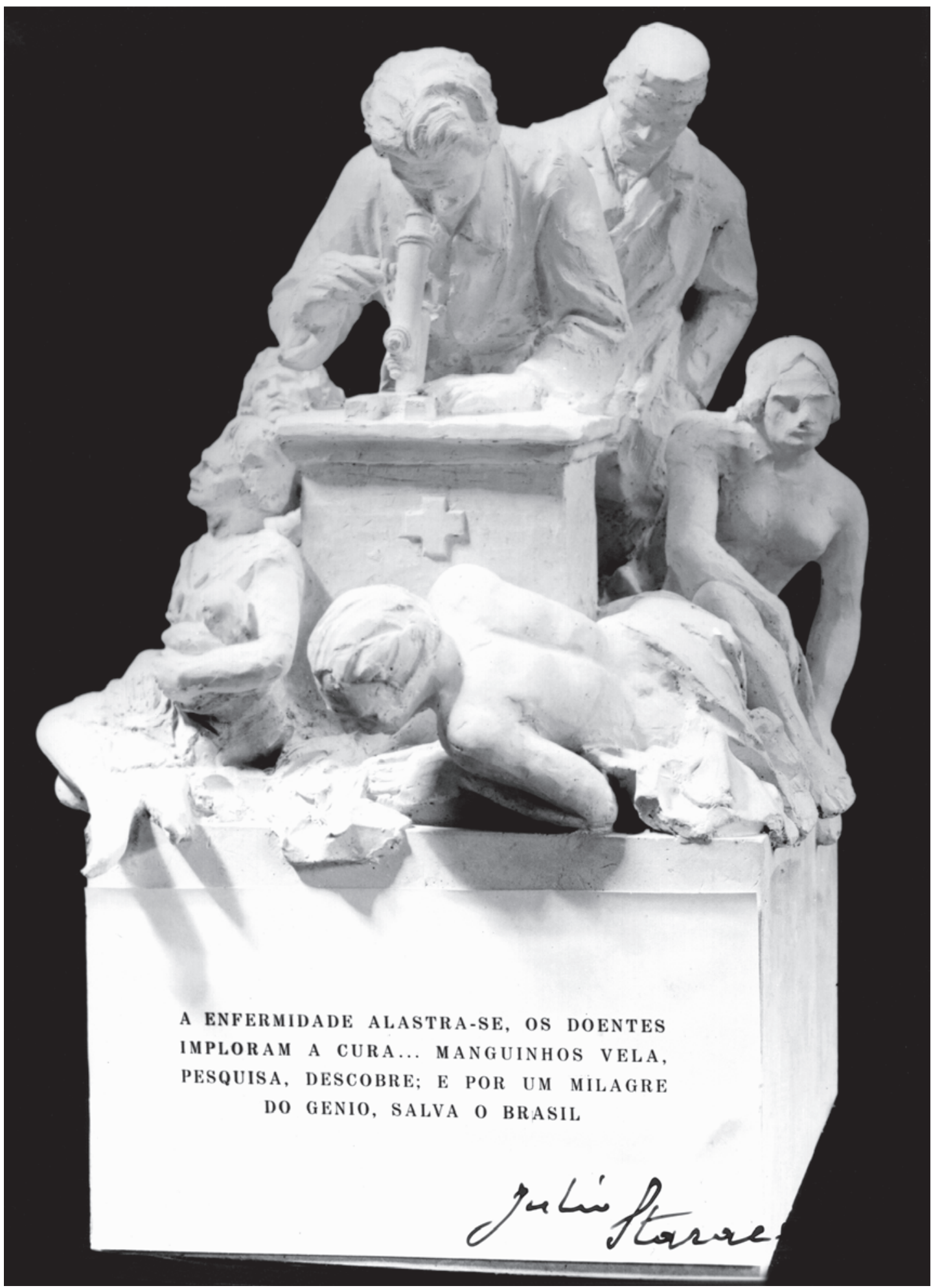

Detalhe do projeto de Starace: Oswaldo Cruz ao microscópio. 
Dossiê referente a projetos e memoriais descritivos - Projeto Cruz Alves (esboço) Todos os projetos eram apresentados sob pseudônimo, a fim de garantir a lisura do concurso. Essa proposta sobrevaloriza o pedestal e a utilização de altos-relevos, escapando dos padrões acadêmicos da estatuária. Por outro lado, a ilustração escultórica mantém o caráter retratista dos fatos e do personagem, o que é característica dos modelos tradicionais. Esse projeto foi acusado por outro concorrente de plagiar uma peça argentina de 1936, que representava o general Roca. Pode-se dizer, no entanto, que se enquadra nas tendências da época, marcadas pela vertente art déco (Coleção Monumento Oswaldo Cruz Caixa 2, maço 1).
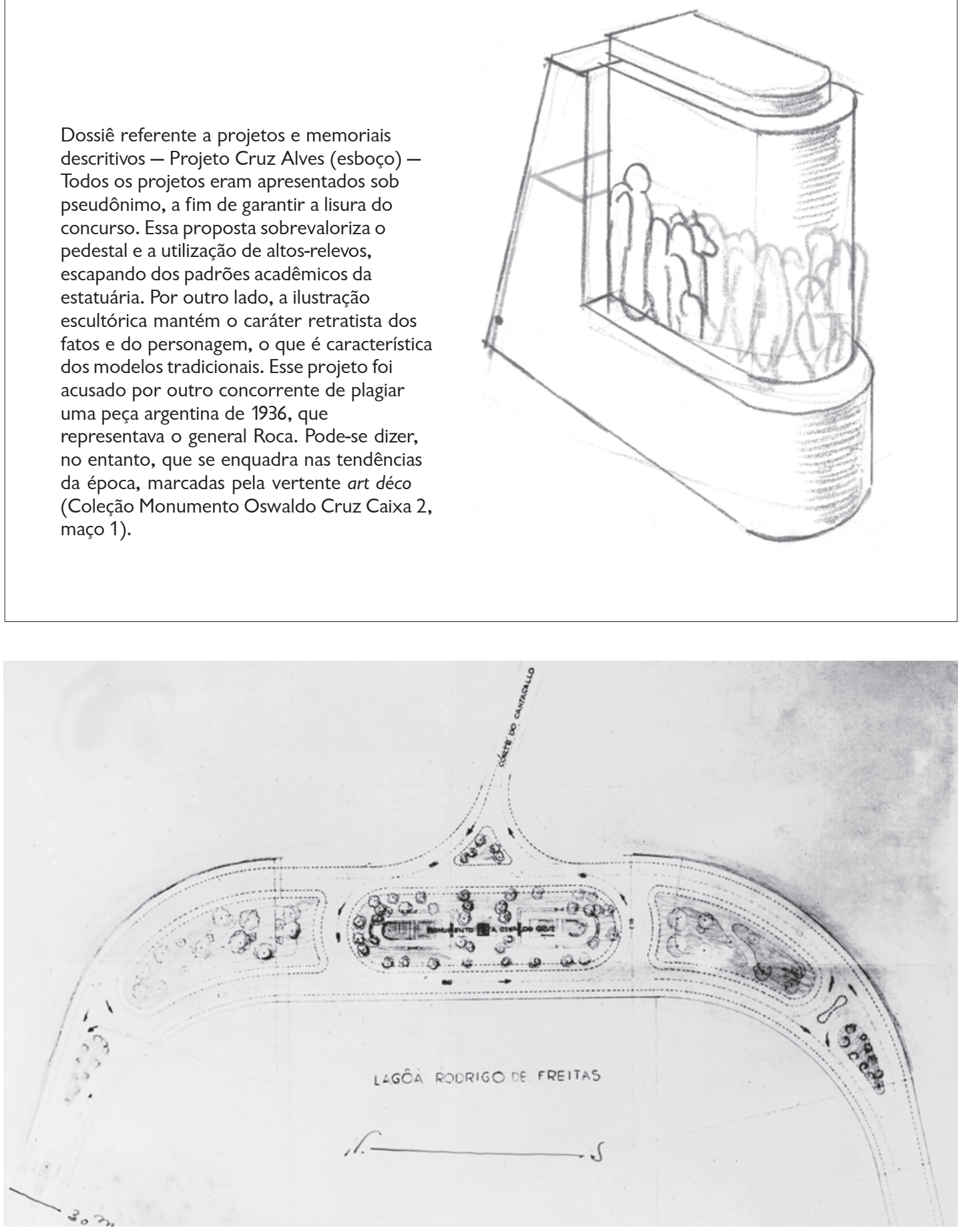

Dossiê referente a projetos e memoriais descritivos. Projeto Audax. Planta-baixa. 


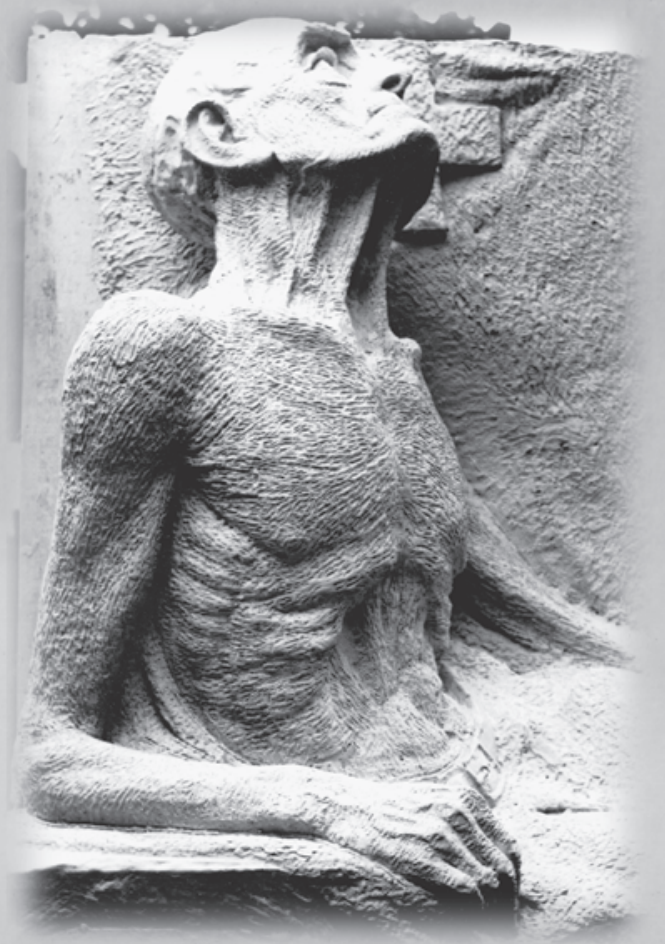

Detalhe: doente moribundo.

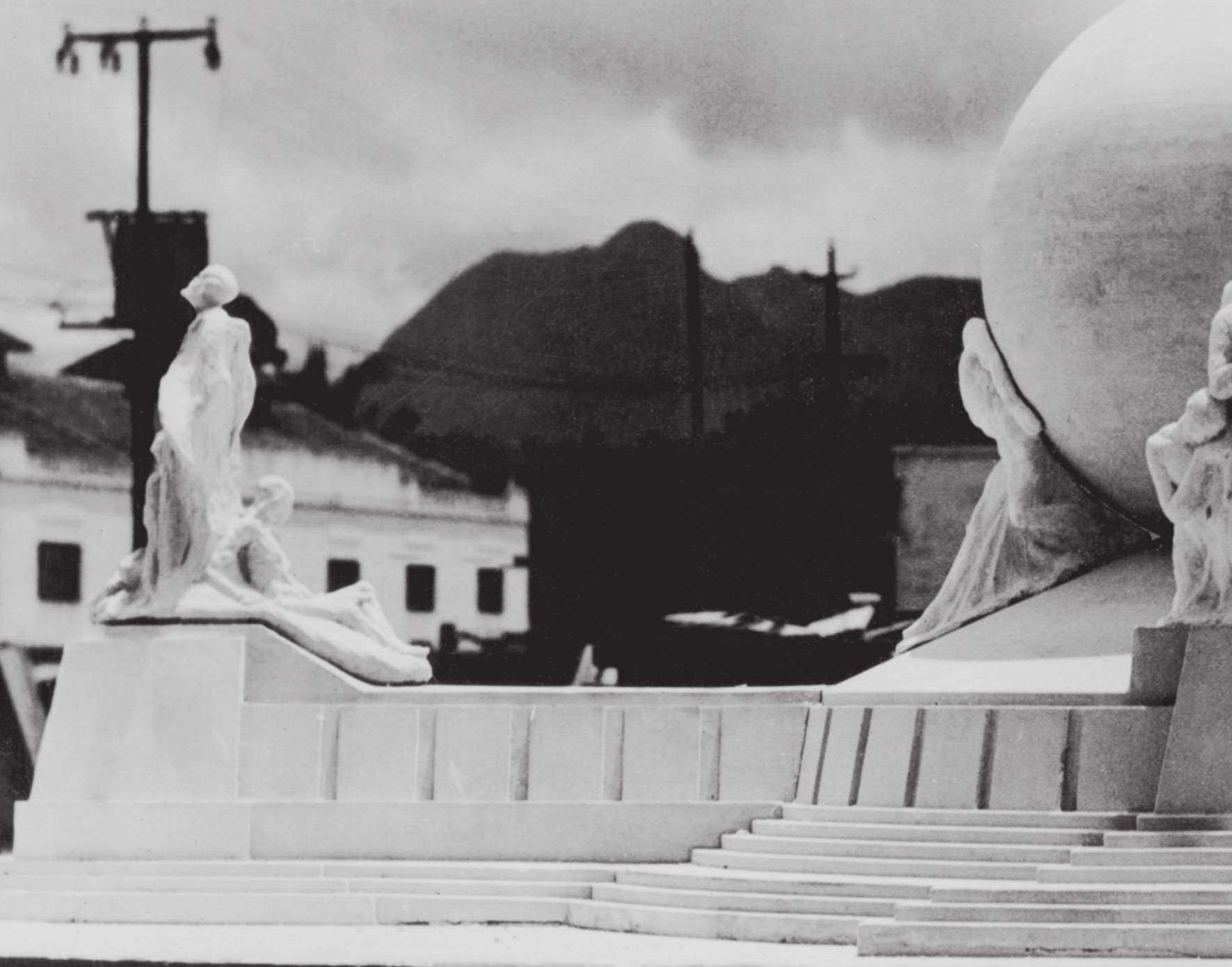


Projeto Audax, vista geral. A parte central sugere a representação do povo agradecido prestando homenagem a Oswaldo Cruz. Do lado esquerdo, o projeto propõe a representação da caridade, apresentando enfermos que suplicam a Deus, ao lado de um religioso em referência à campanha de Santos de 1899. Do lado direito, a ilustração escultórica contempla o socorro aos doentes de febre amarela. A esfera em posição de maior destaque é sustentada por Hércules, que representa diversas virtudes: esforço titânico, perfeição, caráter, cultura, dedicação, amizade, altruísmo, luz de todas as luzes. O projeto recorre, igualmente, a uma solução alegórica, valorizando a agonia da doença, como se vê no detalhe do trabalho escultórico. Além disso, extensa superfície plana valoriza o entorno, como indica a planta-baixa (Caixa 2, maço 1). 


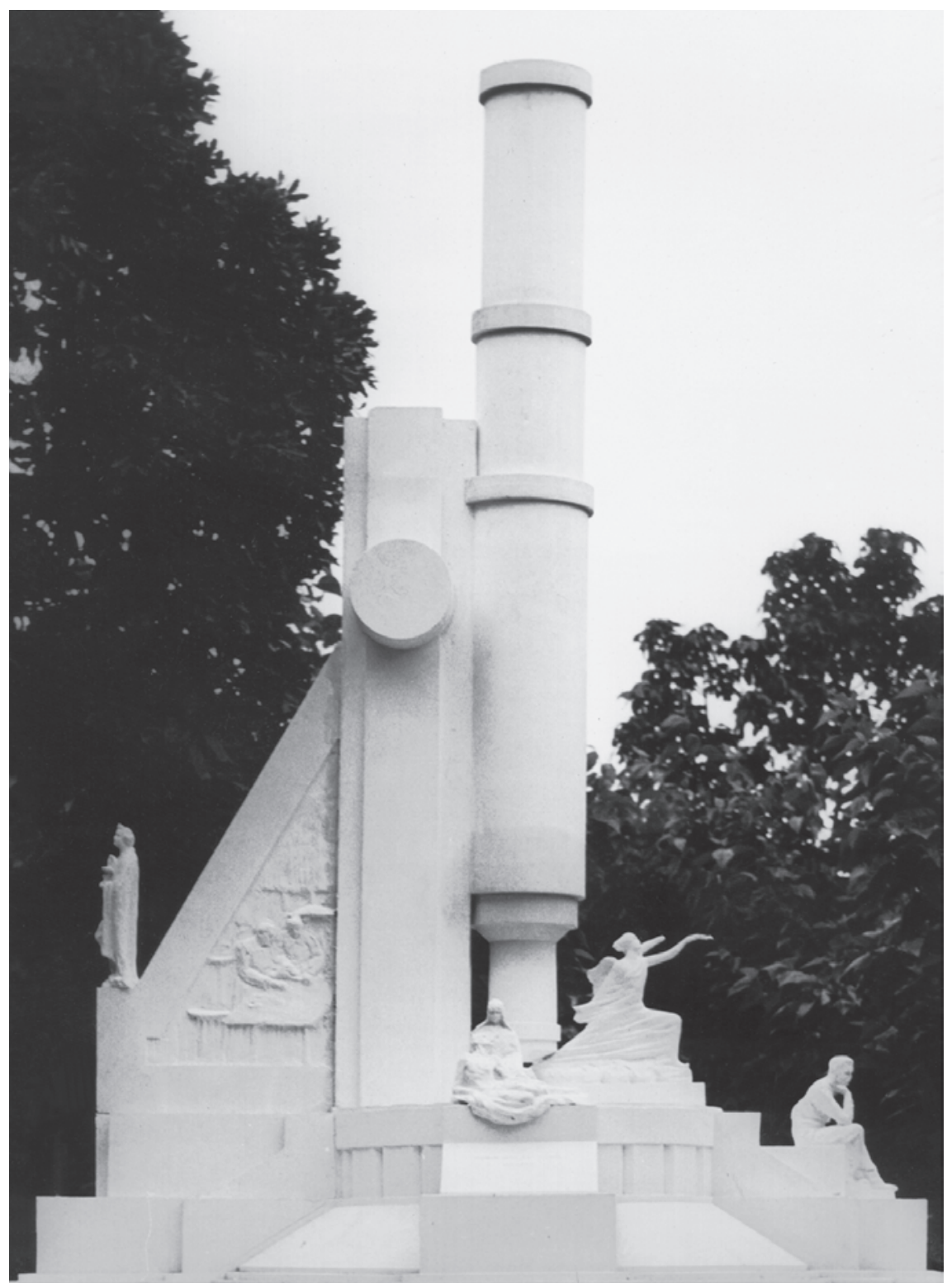

Projeto Volim, vista geral. Valorizava a alegoria em detrimento do retratismo acadêmico. O microscópio central é destacado como signo principal da obra de Oswaldo Cruz. O mesmo sentido alegórico é explorado pelos elementos escultóricos complementares. Na parte anterior da obra está colocada, em primeiro plano, a figura do 'Sábio', cuja solução é alusiva ao célebre Pensador de Auguste Rodin. Tanto Oswaldo Cruz como o projeto escultórico proposto ganham, assim, sua identidade com a cultura ocidental. Em posição de destaque está a 'Vitória alada', representando a obra da medicina como resultado de um combate. Junto à peça central vê-se uma espécie de Pietá: a figura de uma enfermeira ajoelhada com um doente, a alusão à campanha contra a peste bubônica em Santos, em 1899. Essa peça reforça o tom sacralizador da obra. Na parte posterior, há baixos-relevos: do lado direito, uma cena de laboratório, e do esquerdo, uma ilustração do agradecimento à vida. Segue-se uma representação simbólica da febre amarela, acompanhada no extremo pela figura da 'Medicina, mãe do mestre’; em posição relacionada por contigüidade à do Sábio, costura a alegoria e contempla o projeto. O microscópio estilizado projeta-se como um canhão a combater as doenças e seus agentes na posição mais central da proposta, sem ofuscar a vitória e a medicina e o saber na composição. Oswaldo Cruz e o microscópio tornam-se a metáfora do saber e o tema ganha feições de proeza militar (Caixa 2, maço 1). 